\title{
Understanding premixed flame chemistry of gasoline fuels by comparing
}

\section{quantities of interest}

\author{
Hatem Selim $^{\mathrm{a}^{*}}$, Samah Y. Mohamed ${ }^{\mathrm{a}}$, Alaa E. Dawood ${ }^{\mathrm{a}}$, S. Mani Sarathy ${ }^{\mathrm{a}}$ \\ ${ }^{a}$ King Abdullah University of Science and Technology (KAUST), Clean Combustion Research Center (CCRC), \\ Thuwal, Kingdom of Saudi Arabia
}

\begin{abstract}
Gasoline fuels are complex mixtures that vary in composition depending on crude oil feedstocks and refining processes. Gasoline combustion in high-speed spark ignition engines is governed by flame propagation, so understanding fuel composition effects on premixed flame chemistry is important. In this study, the combustion chemistry of low-pressure, burner-stabilized, premixed flames of two gasoline fuels was investigated under stoichiometric conditions. Flame speciation was conducted using vacuum-ultraviolet synchrotron photoionization time-of-flight molecular beam mass spectroscopy. Stable end-products, intermediate hydrocarbons, and free radicals were detected and quantified. In addition, several isomeric species in the reaction pool were distinguished and quantified with the help of the highly tunable synchrotron radiation. A comparison between the products of both flames is presented and the major differences are highlighted. Premixed flame numerical simulations were conducted using surrogate fuel kinetic models for each flame. Furthermore, a new approach was developed to elucidate the main discrepancies between experimental measurements and the numerical predictions by comparing quantities of interest.
\end{abstract}

Keywords: Combustion Chemistry, FACE fuels, Photoionization Mass Spectroscopy, Laminar Premixed Flame, Gasoline Surrogates

\footnotetext{
${ }^{*}$ Corresponding author: E-mail: hatem.selim@kaust.edu.sa 


\section{Introduction}

Enhancing efficiency and reducing environmentally-malignant byproducts of combustion applications pose prominent challenges for the research community. Several advanced combustion engines (ACE) technologies have been developed to ultimately achieve higher efficiency along with lower deleterious emissions, e.g., homogenously charged compression ignition (HCCI) and premixed charged compression ignition (PCCI) engines. Gasoline combustion in these engines is largely controlled by fuel combustion kinetics, so numerous fundamental experimental and numerical research investigations are required to improve ACE technologies. However, the molecular complexity and variability in gasoline fuels makes it challenging to conduct rigorous research on the relationship between fuel composition and combustion kinetics. To this end, the Coordinating Research Council (CRC) formulated a set of Fuels for Advanced Combustion Engines (FACE fuels) to represent a wide range of properties of the real gasoline fuels [1].

Several research studies have been carried out to examine the different combustion properties of gasoline fuels, e.g., ignition delay times (IDT) [2], gasoline autoignition response [3], and laminar burner velocity [4]. Other studies have been primarily concerned with studying the combustion properties of gasoline surrogates [5,6]. Investigations of the FACE fuels combustion started to receive interest lately, e.g., IDT of FACE A and C [7], IDT of FACE F and G [8], and flame speed measurements for FACE C, F, and $\mathrm{J}$ [9]. All the previous studies focused on global combustion properties; however, detailed studies on the combustion chemistry (i.e., intermediate and product species evolution) of gasoline fuels remain scarce.

The development of surrogate fuels for FACE gasoline fuels has received attention for the development of representative chemical kinetic models [10]. This also requires wide range of data on FACE fuel combustion chemistry to help chemical kinetics researchers improving models. In this paper, we investigate the combustion chemistry of two FACE gasoline fuels, namely FACE A and C. These 
two test fuels have the same research octane number $(\mathrm{RON})$ of $\sim 84$ with an octane sensitivity (the difference between the value of research octane number and motor octane number) less than 2 [1]. Sarathy et al. [7] showed that the IDT for FACE A and C and their corresponding primary reference fuel surrogate (PRF 84) are comparable at intermediate and high temperatures, but differences were observed at low temperatures. Therefore, under most engine operating conditions the fuels are expected to have similar heat release behavior, but this is achieved with different chemical compositions; which is for FACE A and C, respectively, n-alkanes (13.2\%, 28.6\%), iso-alkanes $(83.7 \%, 65.1 \%)$, cycloalkanes $(2.4 \%, 1.5 \%)$, aromatics $(0.3 \%, 4.4 \%)$, and olefins $(0.4 \%, 0.4 \%)$ on volumetric molar basis [7].

The goal of the present work is to investigate the relationship between gasoline fuel composition and its combustion properties. The focus is on premixed flame structure and chemistry. This canonical configuration is representative of combustion modes in gasoline-fueled spark ignition engines. To this end, we compare the premixed flame chemistry of FACE A and C fuels, which have similar reactivity but different fuel compositions. The major, intermediate, free radical, and isomeric species within the reaction pool are quantified and the major differences of both flames are highlighted. Furthermore, numerical simulations are performed with detailed chemical kinetics for various surrogate mixtures with the aim of determining the required level of chemical fidelity needed to reproduce the flame chemistry of the real gasoline fuels. Performing such a detailed study for complex fuels poses challenges in presentation and interpretation of results, so a new methodology is developed to compare and elucidate quantities of interest that relate fuel composition to flame chemistry.

\section{Methodologies}

\subsection{Experimental}

\subsubsection{Experimental Setup and Flame Conditions}

The experiments were carried out at the 9.0.2 Chemical Dynamics Beamline at the Advance Light Source (ALS) of the Lawrence Berkeley National Laboratory (LBNL). The experimental setup consists 
of a McKenna burner with a diameter of 6-cm stabilizing laminar premixed flame placed in a pressurecontrolled vacuum chamber. Performing the experiments at low pressure allows the flame to sustainably detach from the burner surface, which advantageously thickens the flame zone and provides more details about the flame chemistry. The sampled gases formed a molecular beam via a quartz sampling cone followed by a skimmer collimator. The flame speciation occurred after photoionization of the sampled molecules using the highly-tunable monochromatic vacuum-ultraviolet synchrotron light provided by the ALS. Analysis of the ionized gases took place in a 1.3-m time-of-flight (TOF) mass spectrometer. More details about the experimental setup and the synchrotron light are available elsewhere [11,12]. The flame of each fuel was set at a stoichiometric condition and the flame chamber was at pressure of 20 Torr. The reactants flow rates were controlled via calibrated MKS thermal flow controllers. The liquid fuels were pre-vaporized and diluted with $50 \%$ of Argon. The flow conditions of FACE A flame are $1.737 \mathrm{slm}$ of oxygen, $1.899 \mathrm{slm}$ of argon, and $1.032 \mathrm{ml} / \mathrm{min}$ of liquid FACE A, while the conditions for FACE C flame are $1.734 \mathrm{slm}$ of oxygen, $1.897 \mathrm{slm}$ of argon, and $1.033 \mathrm{ml} / \mathrm{min}$ of liquid FACE C.

\subsubsection{Data Processing}

Cold-flow pre-known gas mixtures were used to calibrate the time of flight with the mass of the detected ions. The mass discrimination and fragmentation factors were calculated using the cold-flow scans of both the fuel and the pre-known gas mixtures. The raw signals obtained from the TOF were corrected for the contributions of the fragmentation and elemental isotopes of ${ }^{13} \mathrm{C}^{+}$and ${ }^{18} \mathrm{O}^{+}$. The corrected signals were then used for the calculations of the mole fractions using the mass discrimination factors (MDF) and photoionization cross sections (PICS). Burner scans between $8 \mathrm{eV}$ to $17 \mathrm{eV}$ were performed to differentiate between species with different ionization energies; each burner scan ends at $30 \mathrm{~mm}$ height above burner (HAB). An energy scan was conducted between $8 \mathrm{eV}$ to $12 \mathrm{eV}$ to differentiate isomeric species. More details about the data processing starting from the raw TOF signals until the mole fraction calculations are presented elsewhere [13]. The temperature profiles were determined via the 
proportionality between the local temperature at the sampling location and the pressure of the chamber behind the sampling cone [14]. The constant of proportionality was determined by the measurement of the temperature at $30 \mathrm{~mm}$ using Pt-Pt13\% Rh R-type thermocouple and radiation corrections were calculated based on the study of Shaddix [15], while the uncertainty in the measured temperature is \pm 50 $\mathrm{K}$. The uncertainty in mole fraction calculations ranges between $15-30 \%$ for species with well-known PICS, and for other species with higher uncertainty can be up to a factor of 2 [16].

\subsection{Numerical Simulations}

The examined flames were simulated using the PREMIX code of CHEMKIN-PRO software [17]. The reaction mechanism of [7,18] was adopted. A small GRAD and CURV (less than 0.05) were used and grid-independence was verified with more than 500 grid points. Two surrogate fuels were used for the simulations of each flame. The first surrogate is a simple two component primary reference fuel (PRF 84) which consists of $16 \%$ n-heptane and $84 \%$ iso-octane on volumetric molar basis. PRF 84 is chosen because it matches the RON of both FACE A and C. In addition, one 5-component surrogate was chosen for each fuel based on the recommendation of Ahmed et al. [10]; surrogate of FACE gasoline A (FGA) and surrogate of FACE gasoline C (FGC). The composition of each surrogate is listed in the Supplementary Material. A numerical investigation, presented in the Supplementary Material, showed that the effect of pressure on the flux analysis of the mechanistic pathways of each surrogate component is minimal. The comparisons were conducted between the two flame results and the numerical predictions with each surrogate fuel. Furthermore, comparisons were performed using a new approach presented in this paper, which is concerned with comparing the main features of the species mole fraction profiles (i.e., quantities of interest). 


\subsection{Comparing Quantities of Interest}

The concept of using specific features of data sets, called quantities or interests (QoI) [19] or data attributes [20], to facilitate comparisons between complex data and models is used in this paper. In this study, the data are speciation profiles for stable/unstable intermediate species generated within the reacting flow, which typically have similar profile trends. Consequently, the traditional method of comparing experimental and simulated data on graphs [16] obscures the prominent features of each profile and hinders identification of interesting qualitative and quantitative trends. Additional complications are present with complex fuels, such as gasoline, wherein dozens of intermediate species are produced.

In this paper, we propose a new approach that allows a comprehensive comparison between the results of FACE A and C flames. In this approach, we break down the reaction zone into sub-reaction-zones, wherein each species produces a specific perpetual trend from the chemical kinetics perspective. These sub-reaction-zones are defined as the region of initial formation, a rise in production, a maximum value, a rapid destruction, and finally a slow depletion. Using the QoI of our study, we define seven factors

(QoI factors) that digitize the main differences between the features of each sub-reaction-zone of any two species profiles. The comparison between the QoI factors profoundly highlights the differences between the two profiles and facilitates linking them with the chemical kinetics of the rest of the species. Figure 1 shows a sketch of a two arbitrary profiles and describes how the QoI factors are defined. 


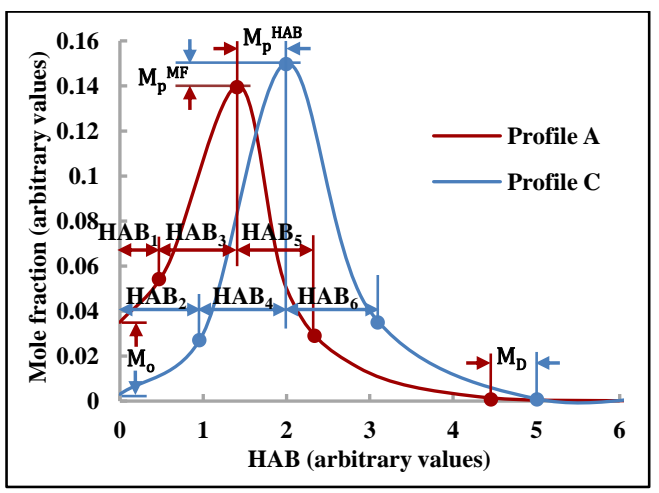

Figure 1. Sketch highlights the values used in the calculations of the QoI factors.

The "M" factors represent the difference between two mole fraction or HAB magnitudes normalized against the value of the reference species (profile $A$ is the reference in Fig. 1). The " $R$ " factors denote the difference between two rates of production/consumption of the mole fraction to reach a specific value normalized against the rate of the reference species.

The difference between the magnitude of the mole fractions at $\mathrm{HAB}=0\left(\mathrm{MF}_{0}{ }^{\mathrm{A}}, \mathrm{MF}_{0}{ }^{\mathrm{C}}\right)$ is described via the $\mathrm{M}_{\mathrm{O}}$ factor. Several physical/chemical aspects could affect this factor, e.g., the chemical/thermal breakdown of the fuel within the burner hot surface, the upstream diffusion of the active radicals towards the burner surface, the experimental error due to the fuel fragmentation during the ionization [13], and the probe perturbation effects which are described previously to be substantial near the burner surface [21]. The species production region is broken down into two segments. The rate of the initial species production is represented via the $R_{15 P}$ factor, and it is defined as the difference in HAB required to attain $15 \%$ of the peak mole fraction of the two profiles. This factor can be affected by the probe perturbation near the burner surface, the upstream diffusion of radicals, and the reaction of long-chain intermediate species with other species/radicals. Because of the numerous sources of uncertainty near the burner surface, the first two factors $\mathrm{M}_{\mathrm{O}}$ and $R_{15 P}$ are the highest ambiguity-laden in the flame zone. The factor $\mathrm{R}_{\text {Pro }}$ denotes the primary species rate of production within the active-radicals-rich reaction zone. This factor is determined via the difference between the rates to reach the peak value of the mole 
fraction. The differences between the maximum mole fraction value $\left(\mathrm{MF}_{\max }{ }^{\mathrm{A}}, \mathrm{MF}_{\max }{ }^{\mathrm{C}}\right)$ and the $\mathrm{HAB}$ to reach the maximum are given via the factors $\mathrm{M}_{\mathrm{P}}{ }^{M F}$ and $\mathrm{M}_{\mathrm{P}}{ }^{H A B}$, respectively. The difference between the primary consumption rates of the two profiles within the reaction zone is defined via the $\mathrm{R}_{75 \mathrm{C}}$ factor, which is defined as the difference between the rates of both profiles to reach $75 \%$ consumption of the peak value. The final factor, $M_{D}$, represents the distance required to reach the depletion point of the species of interest; it is prescribed as the difference between the HAB required to reach $99 \%$ consumption of the peak value $\left(\mathrm{HAB}_{99 \%}{ }^{\mathrm{A}}, \mathrm{HAB}_{99 \%}{ }^{\mathrm{C}}\right)$. The seven QoI factors are mathematically defined according along with a brief description of their physical meaning in table 1.

Table 1

Summary of the mathematical and physical definition of the QoI factors

\begin{tabular}{|c|c|}
\hline QoI factor & What each factor represents \\
\hline $\mathrm{M}_{\mathrm{O}}=1-\frac{\mathrm{MF}_{0}^{\mathrm{C}}}{\mathrm{MF}_{0}^{\mathrm{A}}}$ & $\begin{array}{l}\text { The difference between mole fraction magnitudes } \\
\qquad \text { at } \mathrm{HAB}=0\end{array}$ \\
\hline $\mathrm{R}_{15 \mathrm{P}}=1-\frac{\mathrm{HAB}_{2}}{\mathrm{HAB}_{1}}$ & $\begin{array}{l}\text { The difference in rate of formation to attain } 15 \% \\
\text { of the species mole fraction peak }\end{array}$ \\
\hline $\mathrm{R}_{\text {Pro }}=1-\frac{\mathrm{HAB}_{4}}{\mathrm{HAB}_{3}}$ & $\begin{array}{l}\text { The difference in rate of formation of the species } \\
\text { within the radicals-rich reaction zone }\end{array}$ \\
\hline $\mathrm{M}_{\mathrm{P}}{ }^{H A B}=1-\left(\frac{\mathrm{HAB}_{2}+\mathrm{HAB}_{4}}{\mathrm{HAB}_{1}+\mathrm{HAB}_{3}}\right)$ & The difference in the location of the species peak \\
\hline $\mathrm{M}_{\mathrm{P}}^{M F}=1-\frac{\mathrm{MF}_{\max }^{\mathrm{C}}}{\mathrm{MF}_{\max }^{\mathrm{A}}}$ & The difference in the value of the species peak \\
\hline $\mathrm{R}_{75 \mathrm{C}}=1-\frac{\mathrm{HAB}_{6}}{\mathrm{HAB}_{5}}$ & $\begin{array}{l}\text { The difference in rate of consumption of the } \\
\text { species to reach } 75 \% \text { destruction of the peak value }\end{array}$ \\
\hline $\mathrm{M}_{\mathrm{D}}=1-\frac{\mathrm{HAB}_{99 \%}{ }^{\mathrm{C}}}{\mathrm{HAB}_{99 \%}{ }^{\mathrm{A}}}$ & $\begin{array}{l}\text { The difference in HAB required to reach the } \\
\text { species depletion ( } 99 \% \text { of the peak value) }\end{array}$ \\
\hline
\end{tabular}

\section{Results and discussion}

In this paper we present the speciation results of 35 species which describe, in detail, FACE A and C flame chemistry; these include the main end-products, namely $\mathrm{CO}, \mathrm{CO}_{2}, \mathrm{H}_{2}, \mathrm{H}_{2} \mathrm{O}, \mathrm{O}_{2}$, and Ar; and 30 
intermediate species. Since the flame chemistry is highly influenced by the radical pool which comprises small intermediate hydrocarbons [22,23], we focus in this paper on presenting the stable/unstable species that control the small radical pool reactivity $\left(\mathrm{C}_{2} \mathrm{H}_{4}, \mathrm{C}_{3} \mathrm{H}_{6}, \mathrm{CH}_{2} \mathrm{O}, \mathrm{C}_{3} \mathrm{H}_{4}-\mathrm{a}, \mathrm{C}_{3} \mathrm{H}_{4}-\mathrm{p}, \mathrm{CH}_{3}, \mathrm{CHO}\right.$, and $\mathrm{C}_{3} \mathrm{H}_{5}$ ). These species poses pivotal roles within the reaction pool, e.g., $\mathrm{C}_{2} \mathrm{H}_{4}$ and $\mathrm{C}_{3} \mathrm{H}_{4}-\mathrm{p}$ are main sources for the formation of the soot precursor $\mathrm{C}_{2} \mathrm{H}_{2}$, while another soot precursor $\mathrm{C}_{3} \mathrm{H}_{3}$ is formed via $\mathrm{C}_{3} \mathrm{H}_{4}$-a. In addition, $\mathrm{CH}_{2} \mathrm{O}$ is a main source of $\mathrm{CHO}$ formation which is a marker of heat release within the flame region [24]. $\mathrm{C}_{3} \mathrm{H}_{6}$ is considered a main source for the formation of $\mathrm{CH}_{3}$ and $\mathrm{C}_{3} \mathrm{H}_{5}$, which also dictate the reactivity of the small radical pool.

\subsection{Major Species profiles}

Figure 2 describes the experimental and numerical mole fraction profiles of the major species of FACE $\mathrm{A}$ and $\mathrm{C}$ stoichiometric flames. The results show good agreement between experimental data and numerical predictions of the two surrogates of each fuel. Despite the different compositions, the simulations with binary PRF surrogate are nearly identical to those of the higher fidelity 5-component surrogates. Therefore, the global fuel reactivity and production of major product species is not highly sensitive to surrogate composition. A noticeable discrepancy was found for measured and simulated hydrogen mole fractions, which can be credited to the high rate of $\mathrm{H}_{2}$ radial diffusivity off the molecular beam, resulting in high uncertainty in its collected ion signal and its calculated MDF. The mole fraction profiles of the rest of the species are presented in the Supplementary Material.

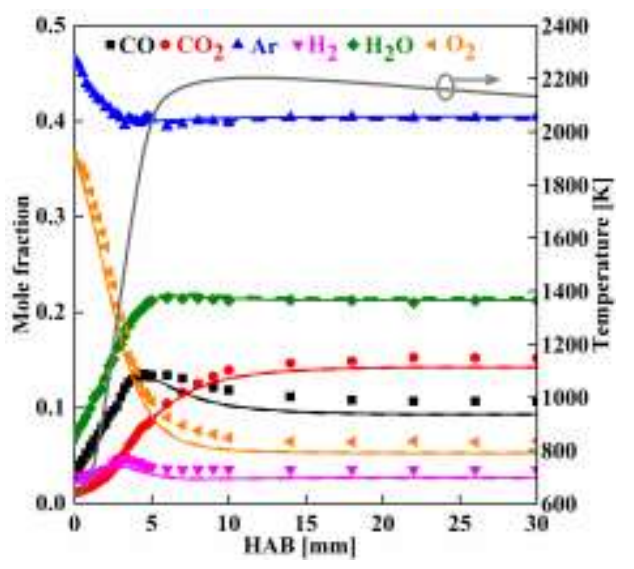




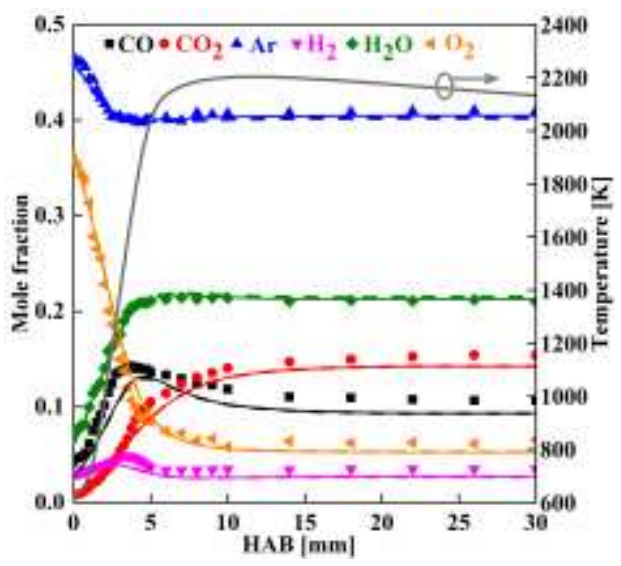

Figure 2. Major species profiles for FACE A (top) and FACE C (bottom) flames, 5-component surrogates (solid lines), PRF 84 (dashed lines).

\subsection{Intermediate Species Comparisons}

The discrepancies of different profiles obtained experimentally and numerically for the intermediate species are quantified using the QoI factor. Three comparisons are conducted between (i) FACE A \& C measurements; (ii) FACE A measurements and FGA/PRF 84 simulations, and (iii) FACE C measurements and FGC/PRF 84 simulations. For (i) and (ii) comparisons, the values for FACE A flame measurements are considered the reference values, while for (iii) comparisons, the FACE C flame results are the reference values. The selected intermediate species are presented in the manuscript, while the remaining QoI comparisons are presented in the Supplementary Material.

Figure 3 shows the QoI factors of three comparison cases for $\mathrm{C}_{2} \mathrm{H}_{4}, \mathrm{C}_{3} \mathrm{H}_{6}$, and $\mathrm{CH}_{2} \mathrm{O}$. For case (i) where experimental flame measurements are compared, the QoI factors depict that $\mathrm{C}_{2} \mathrm{H}_{4}$ and $\mathrm{C}_{3} \mathrm{H}_{6}$ display similar trends. $\mathrm{M}_{\mathrm{O}}$ shows that the mole fractions of both species are $~ 25 \%$ higher in the FACE A flame compared to FACE C. Consequently, the peak value of both species is higher for the FACE A flame. The fact that concentrations of both species are higher for FACE A flame is expected since $\mathrm{C}_{3} \mathrm{H}_{6}$ provides a strong channel for $\mathrm{C}_{2} \mathrm{H}_{4}$ formation via its reaction with $\mathrm{H}$. On the other hand, the rate factors display a slight discrepancy between $\mathrm{C}_{2} \mathrm{H}_{4}$ and $\mathrm{C}_{3} \mathrm{H}_{6}$ behavior, where $\mathrm{R}_{15 \mathrm{P}}$ shows opposite-sign results. The results show predominance of $\mathrm{CH}_{2} \mathrm{O}$ in the reaction pool of the FACE C flame, where $\mathrm{M}_{\mathrm{O}}, \mathrm{R}_{15 \mathrm{P}}$, 
and $\mathrm{M}_{\mathrm{P}}{ }^{M F}$ display higher values compared to FACE A flame by $\sim 10 \%, 13 \%$, and $23 \%$, respectively, this pattern was exhibited for all the aldehydes presented in the Supplementary Material. For the three species, the peak values are obtained within the same vicinity, as depicted by $\mathrm{M}_{\mathrm{P}}{ }^{H A B}$, which shows zero values except for $\mathrm{C}_{3} \mathrm{H}_{6}$. The consumption of the three species within the two flames present quite similar trends, where $R_{75 C}$ and $M_{D}$ showed positive values in the range of $10 \%$ to $20 \%$, which means that the consumption rates are slower in case of FACE A flame; further discussion on this is given later.

The comparisons for case (ii) between the flame results and the numerical predictions showed that PRF 84 successfully captures the same trends obtained by the 5-component surrogates, with some discrepancies between PRF 84 and FGC results, particularly $\mathrm{R}_{15 \mathrm{P}}$. In general, $\mathrm{R}_{15 \mathrm{P}}$ presents the poorest agreement between the experiments and the numerical predictions. This is attributed to the difference in the reaction pool of the experimental and numerical results, which leads to different mechanistic pathways near the burner surface. Aside from $\mathrm{M}_{\mathrm{O}}$ and $\mathrm{R}_{15 \mathrm{P}}$, the numerical predictions reproduced the experimental data with discrepancies less than $35 \%$ for all factors, except for the depletion point of $\mathrm{CH}_{2} \mathrm{O}$ of FACE C. 


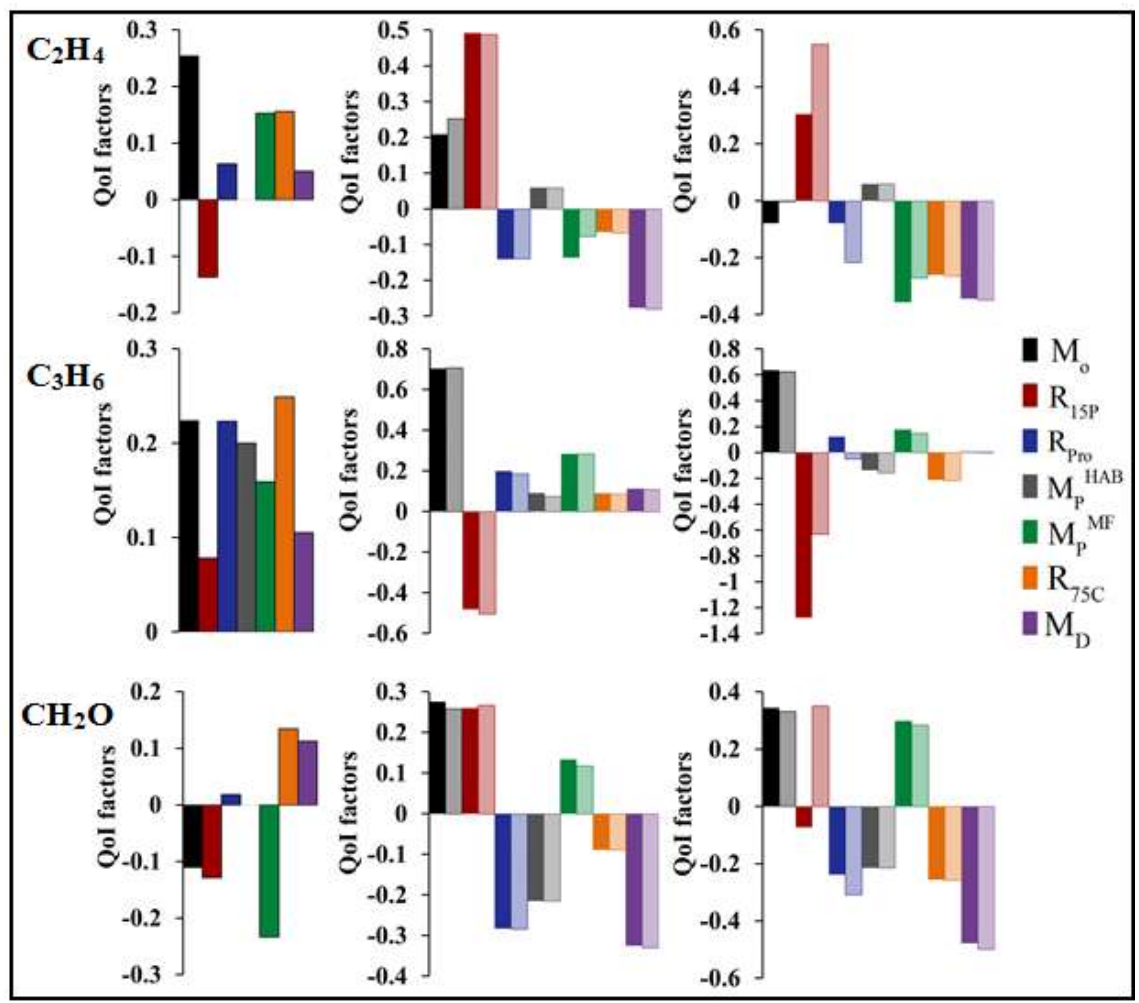

Figure 3. QoI factors of $\mathrm{C}_{2} \mathrm{H}_{4}, \mathrm{C}_{3} \mathrm{H}_{6}, \mathrm{CH}_{2} \mathrm{O}$ for case (i) FACE A vs. FACE C flames $\{$ left $\}$, (ii) FACE A flame vs. FGA (solid)/PRF 84 (hashed) \{middle\}, and (iii) FACE C flame vs. FGC (solid)/PRF 84 (hashed) \{right .

Figure 4 shows the results of the three comparisons for the two isomers of $\mathrm{m} / \mathrm{z}=40$. The comparison between the experimental results shows that both isomers produced relatively similar trends away from the burner surface with all the factors being less than $20 \%$. Subsequently, the discrepancies near the burner surface can be credited to the probe perturbation and fragmentation contributions effects. The numerical comparisons with the experimental results proved that allene $\left(\mathrm{C}_{3} \mathrm{H}_{4}-\mathrm{a}\right)$ profiles are successfully reproduced for both flames by all the surrogates. However, $M_{O}$ and $R_{15 P}$ depict high values due to the difference in the mole fraction magnitude of allene between the experimental and numerical results at $\mathrm{HAB}=0$, which are 110 and $71 \mathrm{PPM}$ for FACE $\mathrm{A}$ and $\mathrm{C}$ flames, respectively; 15, 13, and 15 PPM for FGA, FGC, and PRF 84 simulations respectively. On the other hand, significant discrepancy was observed for propyne $\left(\mathrm{C}_{3} \mathrm{H}_{4}-\mathrm{p}\right)$ mole fraction by all surrogates, which indicates that the reaction mechanism could be responsible for this discrepancy. In a separate study on n-heptane/iso-octane 
mixtures, we found that the rate of $\mathrm{C}_{3} \mathrm{H}_{4}$-p consumption from reaction $\mathrm{C}_{3} \mathrm{H}_{4}$-p $+\mathrm{OH} \leftrightarrow \mathrm{C}_{3} \mathrm{H}_{3}+\mathrm{H}_{2} \mathrm{O}$ is overestimated. In addition, the $\mathrm{H}$-assisted isomerization reaction of allene to form propyne $\mathrm{C}_{3} \mathrm{H}_{4}-\mathrm{p}+\mathrm{H}$ $\leftrightarrow \mathrm{C}_{3} \mathrm{H}_{4}-\mathrm{a}+\mathrm{H}$ is not considered in this reaction mechanism, which leads to lower prediction of propyne mole fractions, supporting figures about the propyne reaction kinetics are given in the Supplementary Material.

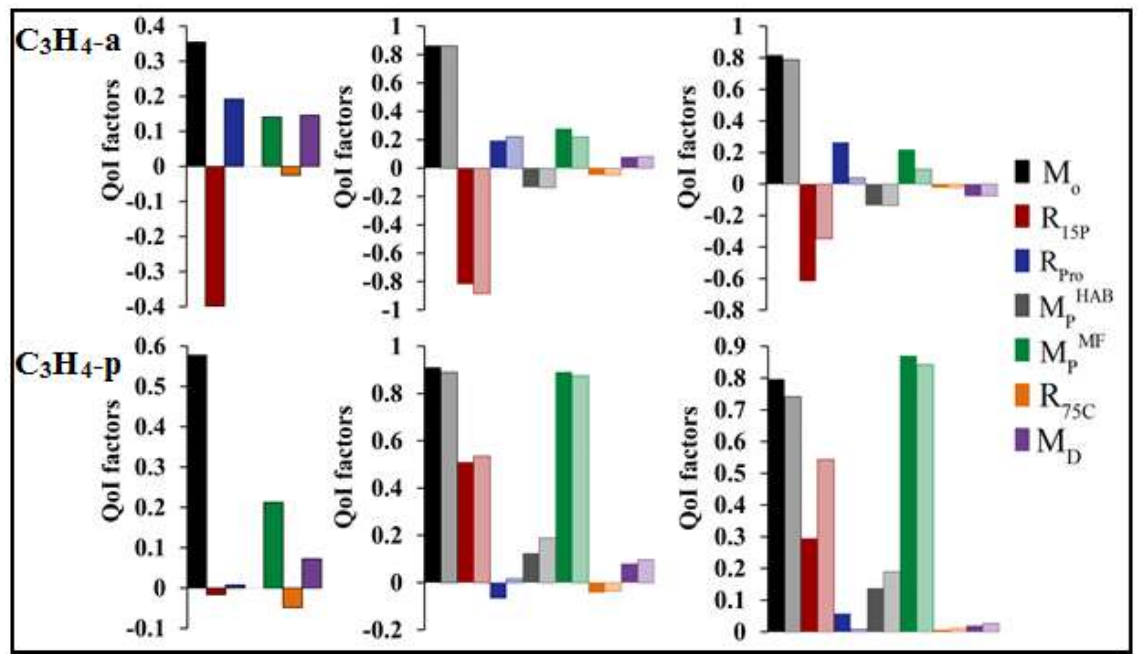

Figure 4. QoI factors of $\mathrm{m} / \mathrm{z}=40$ isomers for case (i) FACE A vs. FACE C flames $\{$ left $\}$, (ii) FACE A flame vs. FGA (solid)/PRF 84 (hashed) \{middle\}, and (iii) FACE C flame vs. FGC (solid)/PRF 84 (hashed) \{right $\}$.

Figure 5 describes the QoI factors for three key radical species in the reaction pool, namely $\mathrm{CH}_{3}, \mathrm{CHO}$ and $\mathrm{C}_{3} \mathrm{H}_{5}$. The comparison between the two flames proved that the magnitudinal differences between the presented radical species are less than $25 \%$. However, the rate differences showed higher disagreement up to $50 \%$ especially for $\mathrm{R}_{15 \mathrm{P}} \cdot \mathrm{M}_{\mathrm{O}}$ and $\mathrm{M}_{\mathrm{P}}{ }^{M F}$ factors showed that higher concentration of $\mathrm{CHO}$ is attained in the reaction pool of FACE C, while $\mathrm{C}_{3} \mathrm{H}_{5}$ is more dominant in FACE A flame. This agrees with the profiles presented earlier of $\mathrm{CH}_{2} \mathrm{O}$ and $\mathrm{C}_{3} \mathrm{H}_{6}$, which are important channels for the formation of these radicals. The profiles of $\mathrm{CHO}$ and $\mathrm{C}_{3} \mathrm{H}_{5}$ justify the slower rates of consumption of the species presented in Fig. 3, where the higher concentration of the resonantly-stable-radical $\mathrm{C}_{3} \mathrm{H}_{5}$ and the lower concentration of the $\mathrm{H}$-formation-radical $\mathrm{CHO}$ weakens the reactivity of the reaction pool of FACE A 
flame. Therefore, the rate of consumption of the intermediate species presented by $R_{75 C}$ and $M_{D}$ is generally lower in the FACE A flame. The comparisons between numerical and experimental results revealed higher differences for $\mathrm{R}_{15 \mathrm{P}}$ especially for $\mathrm{CHO}$ and $\mathrm{C}_{3} \mathrm{H}_{5}$, which is credited to the same reasons mentioned in the discussion of the isomers of $\mathrm{m} / \mathrm{z}=40$. In general, the PRF 84 surrogate successfully reproduces the same results of the 5-component surrogates.

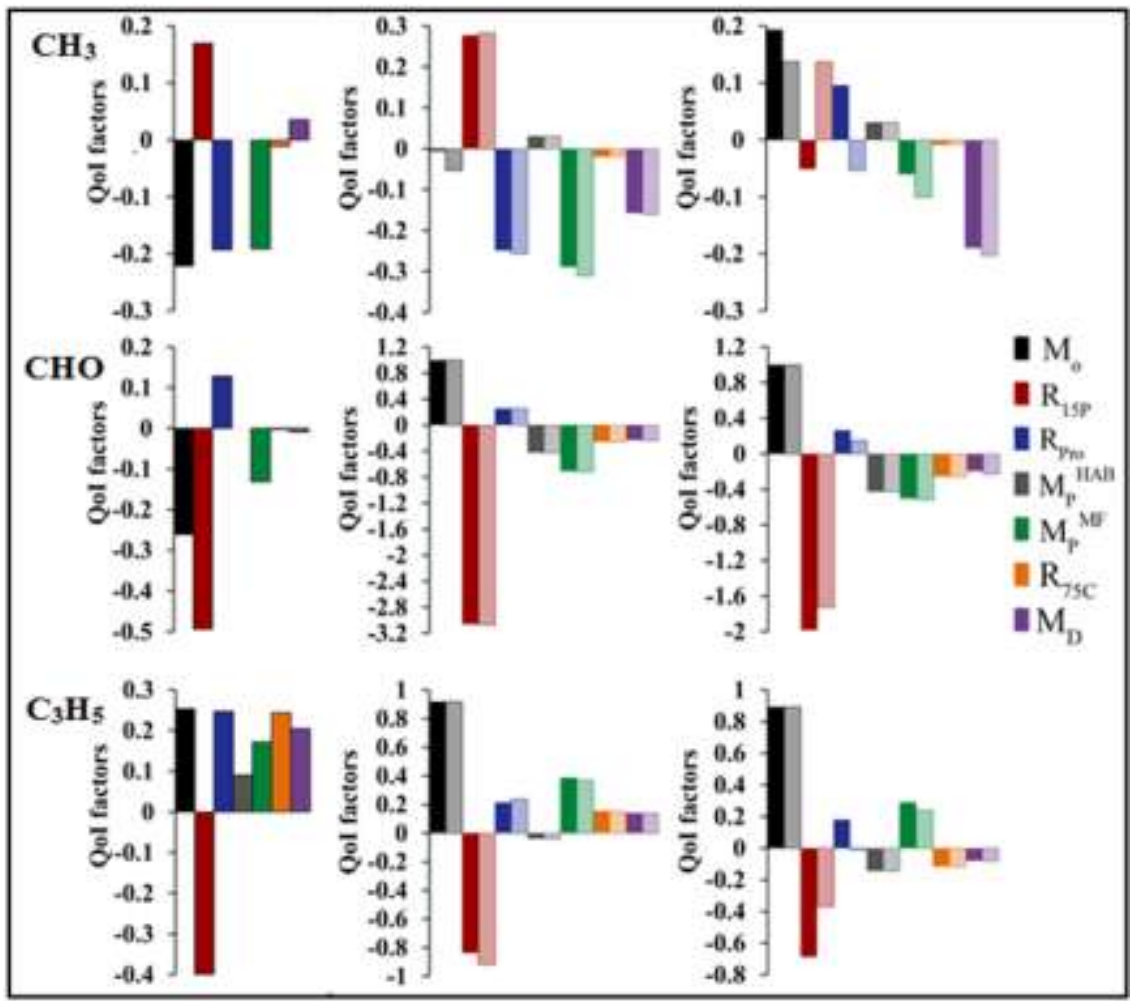

Figure 5. QoI factors of radical species for case (i) FACE A vs. FACE C flames $\{$ left $\}$, (ii) FACE A flame vs. FGA (solid)/PRF 84 (hashed) \{middle\}, and (iii) FACE C flame vs. FGC (solid)/PRF 84 (hashed) $\{$ right $\}$.

\section{Conclusions}

This study investigated the combustion chemistry of FACE A and C stoichiometric laminar premixed flames. A new approach of comparing quantities of interest (QoI) was developed to determine the main discrepancies between the intermediate species profiles of both flames and the numerical simulations. This approach is more informative and presents precise reasoning for the discrepancies between numerical and experimental results with respect to the local physical and chemical conditions. The QoIs 
can be used as guidelines for experimentalists to minimize the sources of errors, and for the modelers to develop more accurate kinetic models. The QoI approach included seven factors that describe the major differences between two typical intermediate species profiles. The comparisons between the two flames proved that the intermediate species pool reactivity of FACE C flame is relatively higher than FACE A, which is attributed to the relative concentrations of radical species $\mathrm{CHO}$ and $\mathrm{C}_{3} \mathrm{H}_{5}$ and their stable counterparts $\mathrm{CH}_{2} \mathrm{O}$ and $\mathrm{C}_{3} \mathrm{H}_{6}$. On the other hand, the comparison between experimental and numerical results showed that the 2-component surrogate (PRF 84) successfully reproduced the results obtained from the 5-component surrogates. The maximum discrepancies between the numerical and experimental simulations were found to be near the burner surface, characterized by $M_{O}$ and $R_{15 P}$. In addition, the numerical simulations produced the profile of $\mathrm{C}_{3} \mathrm{H}_{4}-\mathrm{p}$ with considerable disagreement, which is attributed to deficiency in elementary reactions within the mechanism. The present findings indicate that PRF surrogates comprising n-heptane and iso-octane are suitable surrogates for capturing the detailed flame chemistry of alkane-rich gasoline fuels.

\section{Supplementary Material}

5-component surrogate fuels composition, pressure effect on flux analysis, mole fraction profiles, Quantities of Interest (QoI) definition, QoI factors for intermediate species, and supporting material for propyne $\left(\mathrm{C}_{3} \mathrm{H}_{4}-\mathrm{p}\right)$ kinetics.

\section{Acknowledgments}

This work was performed by the Clean Combustion Research Center with funding from King Abdullah University of Science and Technology (KAUST) and Saudi Aramco under the FUELCOM program.

The measurements were performed at the ALS, LBNL, Berkeley, USA. The ALS is supported by the Director, Office of Science, Office of Basic Energy Sciences, of the U.S. Department of Energy under Contract No. DEAC02-05CH11231. The authors would like to acknowledge Paul Fugazzi for his 
technical assistance and Ahmed Abdelgadir for his modelling assistance. The experimental research support provided by Dr. Nils Hansen from Sandia National Labs. is highly acknowledged.

\section{References}

[1] W. Cannella, M. Foster, G. Gunter, W. Leppard, FACE gasolines and blends with ethanol: Detailed characterization of physical and chemical properties, AVFL-24, Coordinating Research Council, 2014.

[2] B. Gauthier, D. Davidson, R. Hanson, Combust. Flame 139 (2004) 300-311.

[3] G. Kukkadapu, K. Kumar, C.-J. Sung, M. Mehl, W.J. Pitz, Combust. Flame 159 (2012) 3066-3078.

[4] G. Tian, R. Daniel, H. Li, H. Xu, S. Shuai, P. Richards, Energy Fuels 24 (2010) 3898-3905.

[5] D.B. Lenhert, D.L. Miller, N.P. Cernansky, K.G. Owens, Combust. Flame 156 (2009) 549-564.

[6] D. Vuilleumier, H. Selim, R. Dibble, M. Sarathy, Exploration of Heat Release in a Homogeneous Charge Compression Ignition Engine with Primary Reference Fuels. SAE 2013-01-2622.

[7] S.M. Sarathy, G. Kukkadapu, M. Mehl, W. Wang, T. Javed, S. Park, M.A. Oehlschlaeger, A. Farooq, W.J. Pitz, C.-J. Sung, Proc. Combust. Inst. 35 (2015) 249-257.

[8] S.M. Sarathy, G. Kukkadapu, M. Mehl, T. Javed, A. Ahmed, N. Naser, A. Tekawade, G. Kosiba, M. AlAbbad, E. Singh, Combust. Flame 169 (2016) 171-193.

[9] O. Mannaa, M.S. Mansour, W.L. Roberts, S.H. Chung, Combust. Flame 162 (2015) 2311-2321.

[10] A. Ahmed, G. Goteng, V.S.B. Shankar, K. Al-Qurashi, W.L. Roberts, S.M. Sarathy, Fuel 143 (2015) 290300.

[11] T.A. Cool, A. Mcllroy, F. Qi, P.R. Westmoreland, L. Poisson, D.S. Peterka, M. Ahmed, Rev. Sci. Instrum. 76 (2005) 094102.

[12] P.A. Heimann, M. Koike, C.-W. Hsu, D. Blank, X. Yang, A.G. Suits, Y. Lee, M. Evans, C. Ng, C. Flaim, Rev. Sci. Instrum. 68 (1997) 1945-1951.

[13] M. Schenk, L. Leon, K. Moshammer, P. Oßwald, T. Zeuch, L. Seidel, F. Mauss, K. Kohse-Höinghaus, Combust. Flame 160 (2013) 487-503.

[14] H. Selim, S.Y. Mohamed, A. Lucassen, N. Hansen, S.M. Sarathy, Energy Fuels 29 (2015) 2696-2708.

[15] C.R. Shaddix, Correcting thermocouple measurements for radiation loss: a critical review, Sandia National Labs., Livermore, CA (US), 1999.

[16] F.N. Egolfopoulos, N. Hansen, Y. Ju, K. Kohse-Höinghaus, C.K. Law, F. Qi, Prog. Energy Combust. Sci 43 (2014) 36-67.

[17] CHEMKIN-PRO 15112, Reaction Design: San Diego, (2012).

[18] M. Mehl, W.J. Pitz, C.K. Westbrook, H.J. Curran, Proc. Combust. Inst. 33 (2011) 193-200.

[19] K. Braman, T.A. Oliver, V. Raman, Combustion Theory and Modelling 19 (2015) 29-56.

[20] X. You, A. Packard, M. Frenklach, Int. J. Chem. Kinet. 44 (2012) 101-116.

[21] A. Lucassen, N. Labbe, P.R. Westmoreland, K. Kohse-Höinghaus, Combust. Flame 158 (2011) 16471666.

[22] S. Dooley, S.H. Won, J. Heyne, T.I. Farouk, Y. Ju, F.L. Dryer, K. Kumar, X. Hui, C.-J. Sung, H. Wang, Combust. Flame 159 (2012) 1444-1466.

[23] J.A. Miller, G.A. Fisk, Chemical \& Engineering News 65 (1987) 22-46.

[24] P.R. Medwell, P.A.M. Kalt, B.B. Dally, Combust. Flame 148 (2007) 48-61. 


\section{Figure Captions}

(Color figures in electronic version only)

Figure 1. Sketch highlights the values used in the calculations of the QoI factors.

Figure 2. Major species profiles for FACE A (top) and FACE C (bottom) flames, 5-component surrogates (solid lines), PRF 84 (dashed lines).

Figure 3. QoI factors of $\mathrm{C}_{2} \mathrm{H}_{4}, \mathrm{C}_{3} \mathrm{H}_{6}, \mathrm{CH}_{2} \mathrm{O}$ for case (i) FACE A vs. FACE C flames \{left \}, (ii) FACE A flame vs. FGA (solid)/PRF 84 (hashed) \{middle\}, and (iii) FACE C flame vs. FGC (solid)/PRF 84 (hashed) $\{$ right $\}$.

Figure 4. QoI factors of $\mathrm{m} / \mathrm{z}=40$ isomers for case (i) FACE A vs. FACE C flames \{left $\}$, (ii) FACE A flame vs. FGA (solid)/PRF 84 (hashed) \{middle\}, and (iii) FACE C flame vs. FGC (solid)/PRF 84 (hashed) $\{$ right $\}$.

Figure 5. QoI factors of radical species for case (i) FACE A vs. FACE C flames \{left , (ii) FACE A flame vs. FGA (solid)/PRF 84 (hashed) \{middle\}, and (iii) FACE C flame vs. FGC (solid)/PRF 84 (hashed) $\{$ right $\}$. 